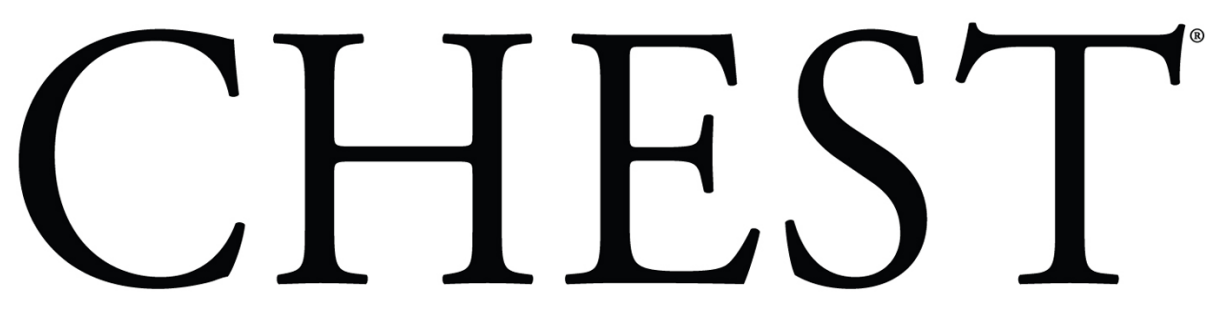

Official publication of the American C ollege of Chest Physicians

Emphysema Presence, Severity, and Distribution Has Little Impact on the Clinical Presentation of a Cohort of Patients With Mild to Moderate COPD

Juan P. de Torres, Gorka Bastarrika, Jorge Zagaceta, Ramón Sáiz-Mendiguren, Ana B. Alcaide, Luis M. Seijo, Usua Montes, Arantza Campo and Javier J. Zulueta

Chest 2011;139;36-42; Prepublished online August 12, 2010; DOI 10.1378/chest.10-0984

The online version of this article, along with updated information and services can be found online on the World Wide Web at: http://chestjournal.chestpubs.org/content/139/1/36.full.html

Chest is the official journal of the American College of Chest Physicians. It has been published monthly since 1935.

Copyright2011by the American College of Chest Physicians, 3300 Dundee Road, Northbrook, IL 60062. All rights reserved. No part of this article or PDF may be reproduced or distributed without the prior written permission of the copyright holder.

(http://chestjournal.chestpubs.org/site/misc/reprints.xhtml) ISSN:0012-3692

A M E R I C A N C O L L E G E O F

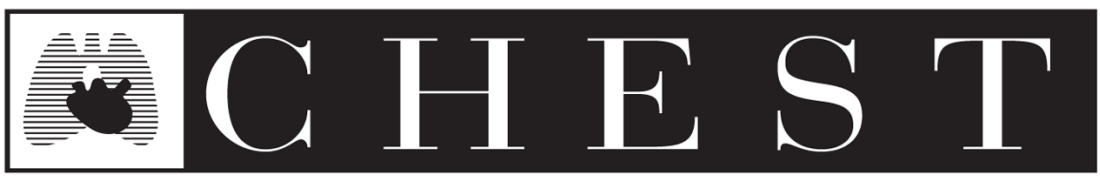
$\begin{array}{lllllllllll}\mathrm{P} & \mathrm{H} & \mathrm{Y} & \mathrm{S} & \mathrm{I} & \mathrm{C} & \mathrm{I} & \mathrm{A} & \mathrm{N} & \mathrm{S}\end{array}$ 


\title{
Emphysema Presence, Severity, and Distribution Has Little Impact on the Clinical Presentation of a Cohort of Patients With Mild to Moderate COPD
}

\author{
Juan P. de Torres, MD; Gorka Bastarrika, MD; Jorge Zagaceta, MD; \\ Ramón Sáiz-Mendiguren, MD; Ana B. Alcaide, MD; Luis M. Seijo, MD; \\ Usua Montes, RN; Arantza Campo, MD; and Javier J. Zulueta, MD, FCCP
}

\begin{abstract}
Background: Phenotypic characterization of patients with COPD may have potential prognostic and therapeutic implications. Available information on the relationship between emphysema and the clinical presentation in patients with COPD is limited to advanced stages of the disease. The objective of this study was to describe emphysema presence, severity, and distribution and its impact on clinical presentation of patients with mild to moderate COPD.

Methods: One hundred fifteen patients with COPD underwent clinical and chest CT scan evaluation for the presence, severity, and distribution of emphysema. Patients with and without emphysema and with different forms of emphysema distribution (upper/lower/core/peel) were compared. The impact of emphysema severity and distribution on clinical presentation was determined.

Results: Fifty percent of the patients had mild homogeneously distributed emphysema $(1.84 ; 0.76 \%-4.77 \%)$. Upper and core zones had the more severe degree of emphysema. Patients with emphysema were older, more frequently men, and had lower $\mathrm{FEV}_{1} \%$, higher total lung capacity percentage, and lower diffusing capacity of the lung for carbon monoxide. No differences were found between the clinical or physiologic parameters of the different emphysema distributions. Conclusions: In patients with mild to moderate COPD, although the presence of emphysema has an impact on physiologic presentation, its severity and distribution seem to have little impact on clinical presentation.

CHEST 2011; 139(1):36-42

Abbreviations: $6 \mathrm{MWD}=6$-min walking distance; $\mathrm{BODE}=\mathrm{BMI}$, obstruction, dyspnea, and exercise capacity; DLCO = diffusing capacity of the lung for carbon monoxide; GOLD = Global Initiative for Obstructive Lung Disease; $\mathrm{HU}=$ Hounsfield units; $\mathrm{IC}=$ inspiratory capacity; LAA $=$ low-attenuation areas; MMRC $=$ Modified Medical Research Council Dyspnea Scale; TLC = total lung capacity
\end{abstract}

$\mathbf{C}$ OPD, a major cause of morbidity and mortality ${ }_{\text {worldwide, }}{ }^{1}$ is believed to result from an abnormal pulmonary inflammatory response to noxious particles or gases. ${ }^{2}$ Clinically, the disease is defined by GOLD (Global Initiative for the Obstructive Lung Disease) as the presence of airway obstruction deter-

Manuscript received April 21, 2010; revision accepted July 13, 2010. Affiliations: From the Department of Pulmonology (Drs de Torres, Zagaceta, Alcaide, Seijo, Campo, and Zulueta), and the Department of Radiology (Drs Bastarrika and Sáiz-Mendiguren), University Clinic of Navarra; and the Centre for Applied Medical Research (Ms Montes), University of Navarra, Navarra, Spain. Correspondence to: Juan P. de Torres, MD, Department of Respiratory Diseases, Clínica Universidad de Navarra, Avda. Pío XII, 36, 31008 Pamplona, Spain; e-mail: jupa65@hotmail.com mined by a postbronchodilator $\mathrm{FEV}_{1} / \mathrm{FVC}<0.70$. Although emphysema is not part of the definition, the GOLD report does mention chronic airway disease and emphysema as different components of COPD, with varying degrees of each in individual patients. ${ }^{2}$ Emphysema is anatomically defined as an abnormal permanent enlargement of the airspace distal to the terminal bronchioles, accompanied by destruction of their walls without obvious fibrosis. ${ }^{3}$

(C) 2011 American College of Chest Physicians. Reproduction of this article is prohibited without written permission from the American College of Chest Physicians (http://www.chestpubs.org/ site/misc/reprints.xhtml).

DOI: $10.1378 /$ chest.10-0984 
The development of software techniques for the analysis of images obtained by CT scanning has enabled researchers to identify and quantify low-attenuation areas (LAA) in vivo that correspond to emphysema. ${ }^{4}$ These techniques have been validated with pathologic and functional correlation studies. ${ }^{5-7}$ They have also been applied in different trials to determine if patients with COPD are candidates for lung volume reduction procedures (surgery, biologic glue, endobronchial valves, or radiofrequency-guided bypass procedures) and in $\alpha_{1}$-antitrypsin deficiency trials to assess response to replacement therapy. ${ }^{8-10}$

COPD is a heterogeneous disease with different phenotypes and with different clinical presentations. ${ }^{11}$ The presence of emphysema on CT imaging usually results in a greater degree of severity of COPD. ${ }^{12}$ Furthermore, varying distributions of emphysema in the lungs have been associated with different clinical presentations. ${ }^{13}$ However, most of the studies that have used CT scan-based software analysis of emphysema have been performed in populations of patients with severe COPD, in which emphysema causes airflow limitation through decreased elastic lung recoil and early airway collapse. ${ }^{3}$ To our knowledge, there are no data describing the impact of emphysema and its distribution and severity on patients with less severe COPD. It is possible that the mechanisms that cause airflow limitation and determine the clinical presentation when the degree of lung parenchyma destruction is mild are different than in more severe disease. The aim of this study was to describe the impact that the presence, distribution, and severity of emphysema has on the clinical presentation of a cohort of patients with mild to moderate COPD (dyspnea, nutritional status, exercise capacity, exacerbation rate, and quality of life).

\section{Materials AND Methods}

This is a cross-sectional observational study of patients diagnosed with COPD recruited from July 2006 to July 2009 in the pulmonary clinic at the University Clinic of Navarra, a tertiary care medical center. Patients with all degrees of airflow limitation were included if they had smoked $\geq 20$ pack-years and had a postbronchodilator $\mathrm{FEV}_{1} / \mathrm{FVC}$ of $<0.70$ after the administration of $400 \mu \mathrm{g}$ of inhaled albuterol. Individuals were excluded if they had a history of asthma, bronchiectasis, TB, or other confounding diseases. The patients were clinically stable (no exacerbation for at least 2 months) at the time of the evaluation. The study was approved by the institution's ethics committee, and all patients signed an informed consent.

\section{Clinical and Physiologic Evaluation}

A personal interview was conducted by trained health-care staff recording age, sex, the presence of significant comorbidities, smoking status, and pack-year history. Spirometry, lung volumes, and diffusing capacity (Vmax 22; Sensormedics Corp; Yorba
Linda, California) were determined following American Thoracic Society recommendations. ${ }^{14}$ The European Community Lung Health Survey values were used as reference. ${ }^{15}$ The 6 -min walking distance (6MWD) was performed following current American Thoracic Society guidelines. ${ }^{16}$ Dyspnea was assessed using the Modified Medical Research Council Dyspnea Scale (MMRC). ${ }^{17}$ BMI was calculated as the weight in kilograms divided by height in meters. ${ }^{2}$ Inspiratory capacity (IC) was measured as previously described. ${ }^{18}$ The ratio between IC and total lung capacity (TLC) was determined from the lung volume measurements. The BODE index (BMI, obstruction, dyspnea, and exercise capacity) was measured and staged in quartiles as previously published by Celli et al. ${ }^{19}$ To determine the health-related quality of life we used the Spanish validated version of the St. George Respiratory Questionnaire. ${ }^{20}$ An exacerbation was defined following the definition by Rodriguez-Roisin, ${ }^{21}$ and exacerbation frequency was evaluated by patient recall over the previous year.

\section{CT Scan Evaluation}

All participants underwent single breath-hold helical CT scan examination of the chest at end-full-inspiration using a 64-row multidetector scanner (Somatom Sensation 64; Siemens Healthcare; Erlangen, Germany) with low-dose CT scan parameters $(120 \mathrm{kVp}, 40 \mathrm{mAs}), 0.33 \mathrm{~s}$ rotation time, 1.3 pitch, $32 \times 0.6 \mathrm{~mm}$ detector collimation, and $64 \times 0.6 \mathrm{~mm}$ slice acquisition by means of z-flying focal spot. ${ }^{22}$ The CT scanner was calibrated periodically by standard methods. Slices were obtained contiguously from the thoracic inlet to the adrenal glands without the use of IV contrast material. From the raw data, 1-mm-thick sections were reconstructed using a soft tissue algorithm kernel (B40f). All CT images were transferred to a satellite console (Leonardo; Siemens Healthcare) for quantitative analysis of lung attenuation.

\section{Quantification of Emphysema}

Low-dose CT scan examinations were reviewed by the study radiologists (G. B., R. S. M.) blinded to patients' clinical data and spirometry results. Images were segmented using a threedimensional automated image-processing software program (Lung Parenchyma Analysis; Siemens Healthcare; Erlangen, Germany).23 After initial three-dimensional segmentation of the lung, this program automatically detects the lung contours and the airways based on threshold values and anatomic knowledge-based algorithm without the need for manual interaction. For emphysema detection, a threshold value of -960 Hounsfield Units (HU) was used, as proposed for multidetector row CT scan examinations. ${ }^{7}$ From the CT scan data analysis, the volume of the segmented lung, the volume of the segmented emphysema, and their ratio (emphysema index, \%LAA -960), were calculated automatically. The software also divides automatically the inner (core) and outer parts (peel) of lung parenchyma, the latter considered as the lung tissue located within $10 \mathrm{~mm}$ of the chest wall. Lung parenchyma was also divided in two parts (upper and lower) for analysis purposes. The upper lung zone was defined as those sections above the main carina, and the lower lung zone was defined as those sections located below the main carina. The \% LAA -960 in each region (upper/lower/core/peel) was calculated from the total percentage. Emphysema was classified as upper or lower and core or peel zone predominant.

\section{Statistical Analysis}

Variables with normal distribution are described by their mean $\pm \mathrm{SD}$, those with nonnormal distribution with their median and 25 th to 50 th percentiles, and categorical variables by their 


\section{COPD patients}

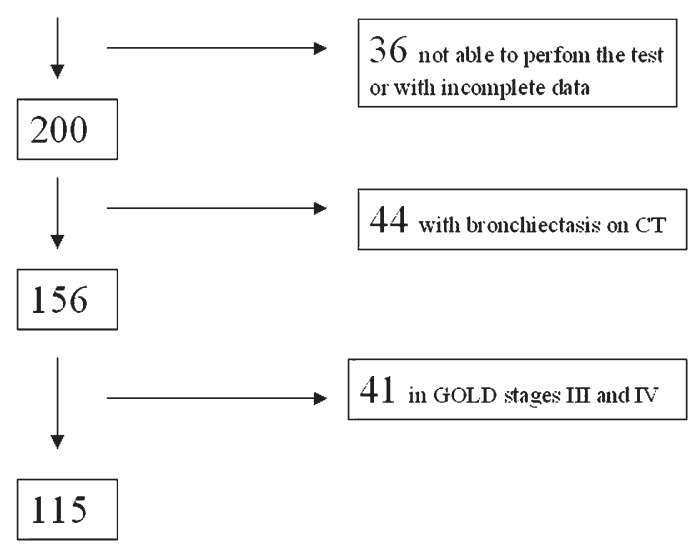

FIGURE 1. Flow chart for the selection of the participating patients. GOLD = Global Initiative for Obstructive Lung Disease.

percentage. The Student $t$ test for independent samples was used to compare means of variables with normal distribution, the Mann-Whitney $U$ rank test for variables without normal distribution, and the Pearson $\chi^{2}$ test for categorical variables. One-way analysis of variance was used to compare the four groups of emphysema distribution, with Tukey post hoc testing to identify significant differences.

Multiple linear regression modeling was used to test for independent associations between clinical features with the extent of emphysema. Variables showing statistical significance in the univariate analysis and potential cofounders were included in the multiple linear regression analysis (age, sex, pack-years, $\mathrm{BMI}, \mathrm{FEV}_{1} \%$, and diffusing capacity of the lung for carbon monoxide [DLCO]). $P$ values $<.05$ were considered statistically significant (software application SPSS version 15; SPSS, Inc; Chicago, Illinois).

\section{RESULTS}

Two hundred thirty-six patients with COPD were included during the study period. We were able to properly register the data and perform the clinical and radiologic evaluation of 200 patients. Of these, 44 subjects were not included in the final cohort because they were found to have bronchiectasis on the chest CT scan. Another 41 patients were excluded because they had advanced-stage COPD (GOLD stages III or IV). Thus, the final study population had 115 patients (Fig 1), whose clinical and radiologic characteristics are shown in Table 1 . This predominantly male population of patients with mild to moderate COPD with low BODE index scores had normal values of BMI and 6MWD and had a limited expression of the disease as represented by low scores in the MMRC and Saint George Respiratory Questionnaire total scores. The degree of emphysema (\% LAA -960) was also low, but up to half of the population had radiologically detected emphysema. Emphysema was equally distributed in the upper and lower zones, as well as in core and peel zones. However, severity was greater in the upper and core zones.
Table 1-Clinical, Physiologic, and Radiologic Characteristics of the Patients

\begin{tabular}{lc}
\hline \hline Characteristics & Patients $(\mathrm{N}=115)$ \\
\hline Age, y & $64 \pm 10$ \\
Sex, male (female) & $97(18)$ \\
Pack-years history, pack-years & $49 \pm 27$ \\
MMRC & $0(0-1)$ \\
BMI, kg/m ${ }^{2}$ & $27 \pm 5$ \\
6MWD, m & $490(420-560)$ \\
Exacerbation in the last y, No. & $0(0-1)$ \\
SRGQ total & $24 \pm 16$ \\
FEV,$\%$ & $75 \pm 15$ \\
FVC, $\%$ & $95 \pm 19$ \\
FEV,/FVC & $58 \pm 9$ \\
TLC, \% & $102 \pm 16$ \\
IC/TLC & $43 \pm 11$ \\
DLCO, \% & $73 \pm 20$ \\
BODE index, U & $0(0-1)$ \\
Patients with emphysema, No. $(\%) ;$ & $58(50) ; 1.84(0.76-4.77)$ \\
severity, LAA -960 HU, \% & \\
Emphysema distribution, No. (\%) & Upper, $29(50)$ \\
& Lower, $29(50)$ \\
& Core, $33(56)$ \\
Emphysema severity, LAA -960 HU, \% & Peel, $25(44)$ \\
& Upper, $1.58(3.00-9.19)$ \\
& Lower, $0.66(1.03-3.54)$ \\
& Core, $1.61(3.59-9.19)$ \\
Peel, $0.63(0.88-2.57)$ \\
\end{tabular}

Values are presented as mean \pm SD or median (25th-50th percentile) unless otherwise noted. $6 \mathrm{MWD}=6$-min walk distance; $\mathrm{BODE}=\mathrm{BMI}$, obstruction, dyspnea, and exercise capacity; DLCO = diffusing capacity of the lung for carbon monoxide; $\mathrm{HU}=$ Hounsfield units; $\mathrm{IC}=$ inspiratory capacity; LAA = low-attenuation areas; $\mathrm{MMRC}=$ Modified Medical Research Council Dyspnea Scale; SGRQ = St. George Respiratory Questionnaire; TLC = total lung capacity.

Table 2 shows the differences found in the clinical parameters between patients with and without emphysema detected by CT scan. Patients with emphysema were older and had higher MMRC scores. As expected, some physiologic parameters (ie, $\mathrm{FEV}_{1} \%$ and DLCO) were worse in patients with emphysema.

The number of women with COPD participating in the study was rather small (only 18), and this precludes a robust sex analysis and comparison between those with and without CT scan-detected emphysema. In any case, the percentage of emphysema tended to be lower in women but was not statistically different than in men ( $1.14 \%$ vs $2.16 \%, P=.07)$. This may be because of the small number of women in the cohort, which also precludes analysis of differences in emphysema distribution by sex.

Table 3 shows the univariate association between emphysema severity and the different clinical and physiologic parameters studied. Emphysema severity correlated with BMI, FVC\%, and TLC\%. A multiple linear regression analysis, including parameters that showed statistical significance in the univariate analysis, did not find statistical associations with \%LAA -960 . 
Table 2-Differences in Clinical and Physiologic Parameters Between Patients With COPD With and Without CT Scan-Detected Emphysema

\begin{tabular}{|c|c|c|c|}
\hline Characteristics & With Emphysema $(\mathrm{n}=58)$ & Without Emphysema $(\mathrm{n}=57)$ & $P$ Value \\
\hline Age, $y$ & $66 \pm 10$ & $61 \pm 10$ & .02 \\
\hline Sex, male (female), \% & $39(29)$ & $61(71)$ & .021 \\
\hline Pack-years history, pack-years & $57 \pm 32$ & $51 \pm 28$ & .22 \\
\hline MMRC & $1(0-1)$ & $1(0-1)$ & .48 \\
\hline $\mathrm{BMI}, \mathrm{kg} / \mathrm{m}^{2}$ & $26 \pm 3$ & $27 \pm 6$ & .15 \\
\hline 6MWD, m & $480(420-560)$ & $505(431-563)$ & .48 \\
\hline Exacerbation in the last year, No. & $0(0-1)$ & $0(0-1)$ & .13 \\
\hline SRGQ total & $23 \pm 17$ & $25 \pm 16$ & .88 \\
\hline $\mathrm{FEV}_{1}, \%$ & $72 \pm 13$ & $77 \pm 16$ & .05 \\
\hline FVC, $\%$ & $106 \pm 15$ & $98 \pm 15$ & .005 \\
\hline TLC, $\%$ & $103 \pm 17$ & $96 \pm 13$ & .04 \\
\hline $\mathrm{IC} / \mathrm{TLC}$ & $42 \pm 11$ & $43 \pm 12$ & .85 \\
\hline DLCO, $\%$ & $65 \pm 19$ & $82 \pm 16$ & .001 \\
\hline BODE index, $U$ & $0(1-2)$ & $0(0-1)$ & .38 \\
\hline
\end{tabular}

Values are presented as mean \pm SD or median (25th-50th percentile) unless otherwise noted. See Table 1 for expansion of abbreviations.

Clinical and physiologic characteristics of patients with different emphysema distributions (upper/lower/ core/peel) are shown in Figure 2. Although patients in the four groups have similar age, $\mathrm{FEV}_{1} \%$, and $\mathrm{BMI}$, they show a great heterogeneity in their physiologic and clinical presentation.

\section{Discussion}

CT scan evaluation of patients with COPD allows a more accurate discrimination of the emphysematous phenotype from other presentations of the disease. To our knowledge, this is the first study that describes the presence of emphysema and its association with physiologic and clinical features in patients with mild or moderate COPD. The main findings of the present report support the theory that the presence of emphysema in patients with COPD has an impact

Table 3-Univariate Association Between Emphysema Severity and the Different Clinical and Physiologic Parameters Studied

\begin{tabular}{lcc}
\hline \hline Characteristics & $\begin{array}{c}\text { Correlation } \\
\text { Coefficient }\end{array}$ & P Value \\
\hline Age, y & 0.12 & .33 \\
Pack-years history, pack-years & -0.52 & .70 \\
MMRC & -0.19 & .14 \\
BMI, kg/m ${ }^{2}$ & -0.33 & .01 \\
6MWD, m & 0.18 & .18 \\
Exacerbation in the last year, No. & 0.12 & .24 \\
SRGQ total & -0.12 & .39 \\
FEV,$\%$ & 0.14 & .27 \\
FVC, \% & 0.38 & .003 \\
FEV $/$ FVC & -0.24 & .06 \\
TLC, \% & 0.29 & .05 \\
IC/TLC & -0.13 & .37 \\
DLCO, \% & 0.03 & .83 \\
BODE index, U & -0.08 & .53 \\
\hline
\end{tabular}

See Table 1 for expansion of abbreviations. on the pathophysiology of this disease. Previous data suggest this relationship exists in patients with severe COPD, ${ }^{13}$ but, to our knowledge, this association has not been previously reported in patients with mild to moderate disease and low grades of emphysema.

Chronic airflow limitation can be caused by increased resistance of the small conducting airways and increased compliance of the lung due to emphysema. ${ }^{2}$ Traditionally, emphysema is associated with the destruction of alveolar walls, resulting in decreased elastic lung recoil and early airway collapse. ${ }^{3}$ It has been estimated that $30 \%$ of the lung must be destroyed by emphysema before symptoms or pulmonary function abnormalities become evident. ${ }^{24}$ Little is known about the presence and impact of mild emphysema on patients with COPD. In this report, $50 \%$ of the patients with COPD included in the study have some degree, albeit low, of CT scan-detected emphysema. In these patients, the physiologic parameters of the disease were worse than in patients without emphysema (ie, lower $\mathrm{FEV}_{1}$, higher TLC, and lower DLCO). Despite these differences, the presence of emphysema had no impact on the clinical presentation of patients in this cohort. This is an important finding previously reported by others ${ }^{12,25}$ in patients with a greater severity of COPD and emphysema. In our entire cohort, the mean percentage of emphysema was $1.84 \%$ (95\% CI, $0.76 \%-4.77 \%$ ), and even such small degrees of lung destruction affected the physiologic presentation of COPD. It is possible that with such small degrees of emphysema, mechanisms other than changes in elastic recoil may be responsible for the physiologic impairment. As elegantly reported by Boschetto et al, ${ }^{12}$ it is possible that patients with COPD who are susceptible to develop emphysema respond differently to inhaled toxic substances, representing a more inflammatory profile with physiologic consequences. A recently published work by 
AGE

80

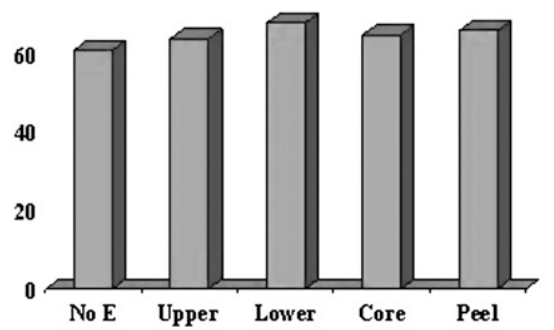

4

2
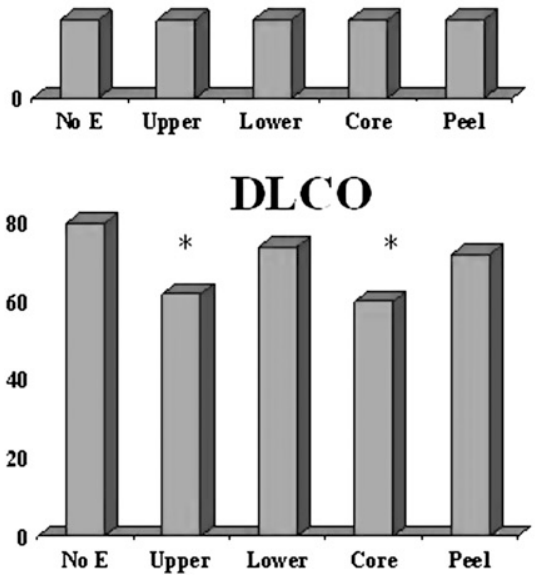

$\mathrm{FEV}_{1} \%$

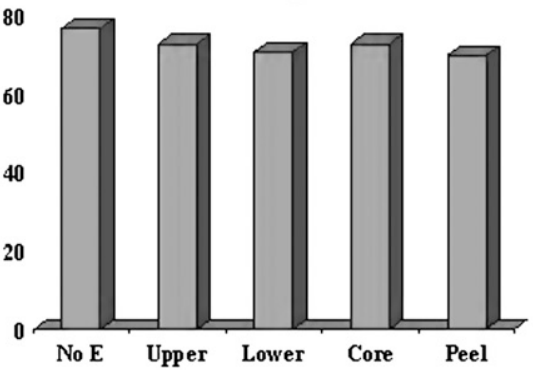

600

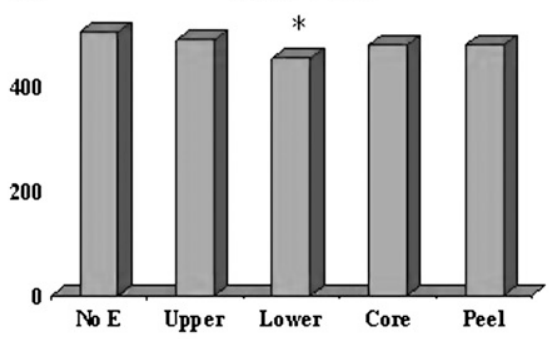

TLC \%

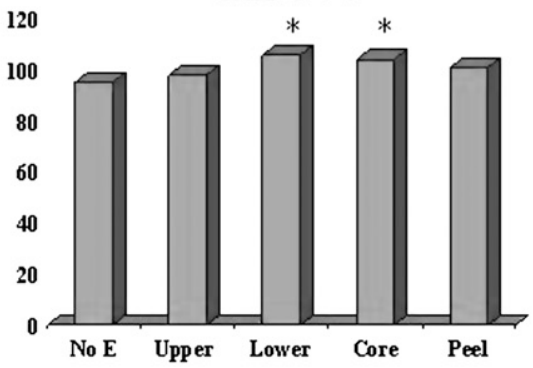

BMII

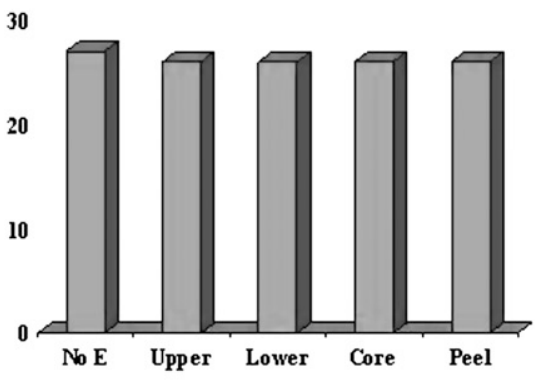

10

8

6

4

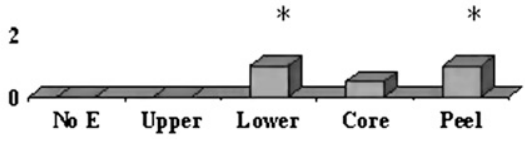

$S G R Q_{\text {tot }}$

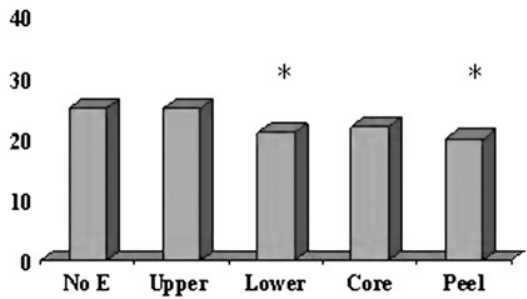

FIGURE 2. Clinical and physiologic characteristics of patients with different emphysema distribution (upper/lower/core/peel). *Indicates a $P$ value $<.05$ compared with patients without emphysema. $6 \mathrm{MWD}=6$-min walk distance; $\mathrm{BODE}=\mathrm{BMI}$, obstruction, dyspnea, and exercise capacity; DLCO = diffusing capacity of the lung for carbon monoxide; MRC = Medical Research Council Dyspnea Scale; SGRQ = St George Respiratory Questionnaire; TLC = total lung capacity.

Papaioannou et $\mathrm{al}^{26}$ found that patients with CT scandetected emphysema have higher levels of systemic oxidative stress and plasma fibrinogen.

Mair et $\mathrm{al}^{13}$ analyzed variables that might predict the severity of emphysema and found that BMI was the best predictor. We found no link between severity of emphysema and BMI in our study, perhaps because the severity of emphysema in our cohort was mild. Indeed, although there was an inverse correlation between BMI and areas of low attenuation, individuals with CT scan-detected emphysema did not have lower BMI values. This information could challenge the knowledge that BMI is tightly associated with emphysema, at least in patients with normal BMI and diffuse emphysema. Unfortunately, our cohort included few patients with a low BMI $(<21)$, precluding a robust analysis of their degree of emphysema.

We used a three-dimensional automated method to quantify the degree of emphysema. A threshold of -960 was chosen based on a recent report showing that on helical multidetector row CT scan examinations performed using $1.25-\mathrm{mm}$ slices with soft tissue kernel obtained at $80 \mathrm{mAs}$, lung areas with attenuation coefficients $<-960$ or -970 HU best reflect the extent of pulmonary emphysema. ${ }^{7}$

Only one study has examined the impact of the distribution of emphysema (upper/lower/core/peel) ${ }^{13}$ on the clinical presentation of patients with severe COPD. However, this has not been shown in other degrees of severity. Additionally, the core/peel distribution has not been proven yet to have any clinical or prognostic usefulness in patients with COPD. Mair et al ${ }^{13}$ reported that the distribution of emphysema related best to the clinical presentation when divided into core/peel predominance. However, this effect was not independent of the severity of emphysema. In the present study, patients with COPD with mild to moderate disease and mild emphysema have a heterogeneous physiologic and clinical presentation of the disease according to their distribution as shown 
in Figure 1. Although different distributions of emphysema seem to impact presentation heterogeneity, these differences were not statistically significant. Therefore, in mild to moderate COPD, the distribution of emphysema does not have an impact on the clinical presentation of the disease as has been reported in other cohorts with more severe disease. ${ }^{13}$

In view of the lack of an effect of emphysema on the clinical presentation in early stages of COPD, it may be argued that the knowledge of its presence is not important. Based on the current study, one could postulate that performing a CT scan in patients with mild or moderate COPD adds little to clinical management. However, we do not know what impact mild degrees of emphysema might have on the natural course of the disease. Furthermore, the presence of emphysema significantly increases the risk of lung cancer in these patients. ${ }^{27}$ For this reason alone, we believe that identifying emphysema on a CT scan in patients with COPD is important for their long-term care.

\section{Study Limitations}

Small sample size, especially the small number of participating women, is a limitation of this study. It is now well known that there are important sex differences in emphysema severity and distribution. Women have less severe emphysema than men, and it is generally centrally distributed with smaller areas of low attenuation. ${ }^{28}$ This limitation precludes an assessment of the role that the presence, severity, and distribution of emphysema might have on the clinical presentation of the disease in women. Knowing that there are consistent sex differences in the clinical presentation of the disease, we believe it is important to further investigate this issue with an appropriate cohort. ${ }^{29}$

Only a small percentage of our patients had determinations of $\alpha_{1}$-antitrypsin levels (54 out of $115,47 \%$ ), all being within normal limits. However, because only $1 \%$ of patients with COPD have $\alpha_{1}$-antitrypsin deficiency, ${ }^{10}$ it seems unlikely that more $\alpha_{1}$-antitrypsin determinations would have had a significant impact on the results.

Failure to ensure the achievement of maximal inspiration during scanning (eg, using spirometry in conjunction with the CT scan) may affect the degree of lung attenuation and account for a degree of variability. However, recent data ${ }^{30}$ indicate that this technique may not be necessary when performing cross-sectional studies because the reproducibility of patients' inspiratory maneuvers is very high. Finally, because our study population is limited to patients with mild to moderate COPD, these findings cannot be extrapolated either to patients with more severe disease or patients with preserved lung function and emphysema.

\section{CONCLUSION}

In conclusion, in this cohort of patients with mild to moderate COPD, the presence of emphysema, regardless of its distribution, has an impact on physiologic parameters but not on the clinical presentation of the disease. Further studies should confirm the importance of our findings.

\section{ACKNOWLEDGMENTS}

Author contributions: $\mathrm{Dr}$ de Torres: contributed to conceiving the idea, enrolling patients, and writing the manuscript.

Dr Bastarrika: contributed to performing and reviewing the lowdose chest CT scan.

Dr Zagaceta: contributed to enrolling patients.

Dr Sáiz-Mendiguren: contributed to performing and reviewing the low-dose chest CT scan.

Dr Alcaide: contributed to enrolling patients.

Dr Seijo: contributed to enrolling patients.

Ms Montes: contributed to performing the questionnaires.

Dr Campo: contributed to enrolling patients.

Dr Zulueta: contributed to enrolling patients and reviewing the manuscript.

Financial/nonfinancial disclosures: The authors have reported to CHEST the following conflicts of interest: Dr Bastarrika receives support from Bayer-Schering, General Electric, Medrad, and Siemens for participating in speaking activities and an industry advisory committee. Drs de Torres, Zagaceta, Sáiz-Mendiguren, Alcaide, Seijo, Campo, and Zulueta and Ms Montes have reported to CHEST that no potential conflicts of interest exist with any companies/organizations whose products or services may be discussed in this article.

Other contributions: This study was approved by the Ethics Committee of the University Clinic of Navarra "Comité de Ética de la Investigación” approval n043/2010. We thank Elena de Miguel, RN, and Teresa Jiménez, RN, for performing the pulmonary function tests.

\section{REFERENCES}

1. Pauwels RA, Rabe KF. Burden and clinical features of chronic obstructive pulmonary disease (COPD). Lancet. 2004; 364(9434):613-620.

2. Global Initiative for Chronic Obstructive Lung Disease. Global Strategy for diagnosis, management and prevention of COPD. (Updated 2008). http://www.goldcopd.com. Accessed July 2009.

3. Celli BR, MacNee W; ATS/ERS Task Force. Standards for the diagnosis and treatment of patients with COPD: a summary of the ATS/ERS position paper. Eur Respir J. 2004;23(6): 932-946.

4. Goddard PR, Nicholson EM, Laszlo G, Watt I. Computed tomography in pulmonary emphysema. Clin Radiol. 1982; 33(4):379-387.

5. Müller NL, Staples CA, Miller RR, Abboud RT. "Density mask". An objective method to quantitate emphysema using computed tomography. Chest. 1988;94(4):782-787.

6. Gould GA, Redpath AT, Ryan M, et al. Lung CT density correlates with measurements of airflow limitation and the diffusing capacity. Eur Respir J. 1991;4(2):141-146.

7. Madani A, Zanen J, de Maertelaer V, Gevenois PA. Pulmonary emphysema: objective quantification at multi-detector row 
CT-comparison with macroscopic and microscopic morphometry. Radiology. 2006;238(3):1036-1043.

8. Edwards MA, Hazelrigg S, Naunheim KS. The National Emphysema Treatment Trial: summary and update. Thorac Surg Clin. 2009;19(2):169-185.

9. Ingenito EP, Wood DE, Utz JP. Bronchoscopic lung volume reduction in severe emphysema. Proc Am Thorac Soc. 2008;5(4):454-460.

10. Silverman EK, Sandhaus RA. Clinical practice. Alpha1antitrypsin deficiency. N Engl J Med. 2009;360(26):2749-2757.

11. Marsh SE, Travers J, Weatherall M, et al. Proportional classifications of COPD phenotypes. Thorax. 2008;63(9):761-767.

12. Boschetto P, Miniati M, Miotto D, et al. Predominant emphysema phenotype in chronic obstructive pulmonary. Eur Respir J. 2003;21(3):450-454.

13. Mair G, Miller JJ, McAllister D, et al. Computed tomographic emphysema distribution: relationship to clinical features in a cohort of smokers. Eur Respir J. 2009;33(3):536-542.

14. American Thoracic Society. Standardization of spirometry: 1994 update. Am J Respir Crit Care Med. 1995;152(3):1107-1136.

15. Roca J, Burgos F, Sunyer J, et al. References values for forced spirometry. Group of the European Community Respiratory Health Survey. Eur Respir J. 1998;11(6):1354-1362.

16. Statement ATS; ATS Committee on Proficiency Standards for Clinical Pulmonary Function Laboratories. ATS statement: guidelines for the six-minute walk test. Am J Respir Crit Care Med. 2002;166(1):111-117.

17. Mahler DA, Weinberg DH, Wells CK, Feinstein AR. The measurement of dyspnea. Contents, interobserver agreement, and physiologic correlates of two new clinical indexes. Chest. 1984;85(6):751-758.

18. Casanova C, Cote C, de Torres JP, et al. Inspiratory-to-total lung capacity ratio predicts mortality in patients with chronic obstructive pulmonary disease. Am J Respir Crit Care Med. 2005;171(6):591-597.

19. Celli BR, Cote CG, Marin JM, et al. The body-mass index, airflow obstruction, dyspnea and exercise capacity index in chronic obstructive pulmonary disease. N Engl J Med. 2004; 350(10):1005-1012.
20. Jones PW, Quirk FH, Baveystock CM, Littlejohns P. A selfcomplete measure of health status for chronic airflow limitation. The St. George's Respiratory Questionnaire. Am Rev Respir Dis. 1992;145(6):1321-1327.

21. Rodriguez-Roisin R. Toward a consensus definition for COPD exacerbations. Chest. 2000;117(5)(suppl 2):398S-401S.

22. Flohr TG, Stierstorfer K, Ulzheimer S, Bruder H, Primak AN, McCollough CH. Image reconstruction and image quality evaluation for a 64 -slice CT scanner with z-flying focal spot. Med Phys. 2005;32(8):2536-2547.

23. Madani A, De MaertelaerV,Zanen J, Gevenois PA. Pulmonary emphysema: radiation dose and section thickness at multidetector CT quantification-comparison with macroscopic and microscopic morphometry. Radiology. 2007;243(1): 250-257.

24. Pratt PC, Kilburn KH. A modern concept of emphysemas based on correlations of structure and function. Hum Pathol. 1970;1(3):443-463.

25. Boschetto P, Quintavalle S, Zeni E, et al. Association between markers of emphysema and more severe chronic obstructive pulmonary disease. Thorax. 2006;61(12):1037-1042.

26. Papaioannou AI, Mazioti A, Kiropoulos T, Tsilioni I, Koutsokera A, Tanou K, et al. Systemic and airway inflammation and the presence of emphysema in patients with COPD. Respir Med. 2010;104(2):275-282.

27. de Torres JP, Bastarrika G, Wisnivesky JP, et al. Assessing the relationship between lung cancer risk and emphysema detected on low-dose CT of the chest. Chest. 2007;132(6): 1932-1938.

28. Martinez FJ, Curtis JL, Sciurba F, et al; National Emphysema Treatment Trial Research Group. Sex differences in severe pulmonary emphysema. Am J Respir Crit Care Med. 2007; 176(3):243-252.

29. de Torres JP, Casanova C, Hernández C, Abreu J, AguirreJaime A, Celli BR. Gender and COPD in patients attending a pulmonary clinic. Chest. 2005;128(4):2012-2016.

30. Newell JD Jr, Hogg JC, Snider GL. Report of a workshop: quantitative computed tomography scanning in longitudinal studies of emphysema. Eur Respir J. 2004;23(5):769-775. 


\section{Emphysema Presence, Severity, and Distribution Has Little Impact on the Clinical Presentation of a Cohort of Patients With Mild to Moderate COPD}

Juan P. de Torres, Gorka Bastarrika, Jorge Zagaceta, Ramón

Sáiz-Mendiguren, Ana B. Alcaide, Luis M. Seijo, Usua Montes, Arantza

Campo and Javier J. Zulueta

Chest 2011;139; 36-42; Prepublished online August 12, 2010;

DOI 10.1378/chest.10-0984

This information is current as of June 27, 2012

Updated Information \& Services

Updated Information and services can be found at:

http://chestjournal.chestpubs.org/content/139/1/36.full.html

\section{References}

This article cites 29 articles, 20 of which can be accessed free at:

http://chestjournal.chestpubs.org/content/139/1/36.full.html\#ref-list-1

\section{Permissions \& Licensing}

Information about reproducing this article in parts (figures, tables) or in its entirety can be found online at:

http://www.chestpubs.org/site/misc/reprints.xhtml

\section{Reprints}

Information about ordering reprints can be found online:

http://www.chestpubs.org/site/misc/reprints.xhtml

\section{Citation Alerts}

Receive free e-mail alerts when new articles cite this article. To sign up, select the "Services" link to the right of the online article.

\section{Images in PowerPoint format}

Figures that appear in CHEST articles can be downloaded for teaching purposes in PowerPoint slide format. See any online figure for directions.

\section{A M E R I C A N C O L L E G E O F}

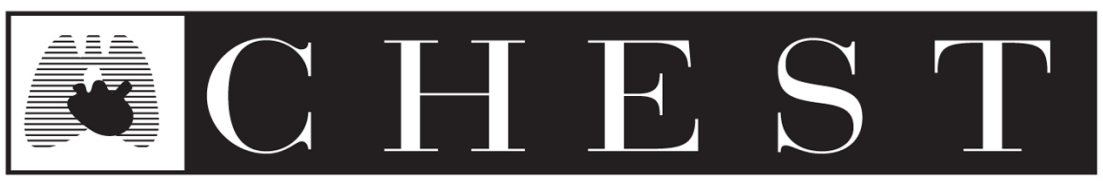
$\mathrm{P}$
H Y
$\mathrm{S} \quad \mathrm{I}$
C I
A $\mathrm{N}$
$\mathrm{S}^{\circledR}$ 